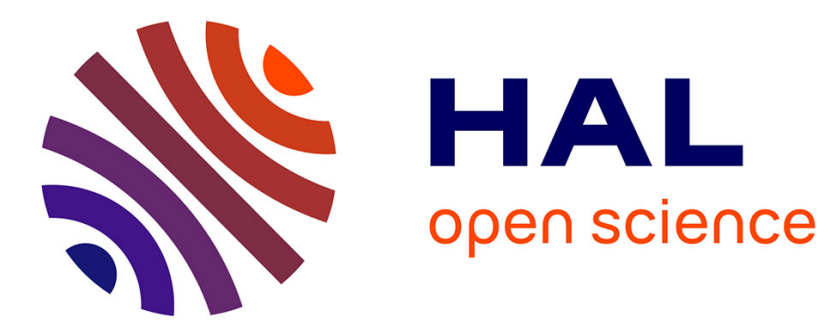

\title{
Time knowledge acquisition in children aged 6 to 11 years and its relationship with numerical skills
}

Florence Labrell, Yann Mikaeloff, Hervé Perdry, Georges Dellatolas

\section{To cite this version:}

Florence Labrell, Yann Mikaeloff, Hervé Perdry, Georges Dellatolas. Time knowledge acquisition in children aged 6 to 11 years and its relationship with numerical skills. Journal of Experimental Child Psychology, 2016, 143, pp.1-13. 10.1016/j.jecp.2015.10.005 . hal-02566723

\section{HAL Id: hal-02566723 \\ https://hal.science/hal-02566723}

Submitted on 7 May 2020

HAL is a multi-disciplinary open access archive for the deposit and dissemination of scientific research documents, whether they are published or not. The documents may come from teaching and research institutions in France or abroad, or from public or private research centers.
L'archive ouverte pluridisciplinaire HAL, est destinée au dépôt et à la diffusion de documents scientifiques de niveau recherche, publiés ou non, émanant des établissements d'enseignement et de recherche français ou étrangers, des laboratoires publics ou privés. 
Dear Author,

Please, note that changes made to the HTML content will be added to the article before publication, but are not reflected in this PDF.

Note also that this file should not be used for submitting corrections. 


\begin{tabular}{|c|c|c|}
\hline 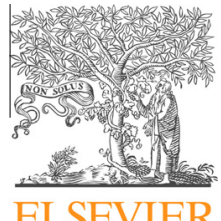 & $\begin{array}{l}\text { Contents lists available at ScienceDirect } \\
\text { Journal of Experimental Child } \\
\text { PSychology }\end{array}$ & 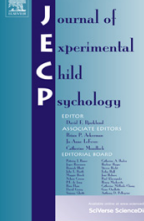 \\
\hline
\end{tabular}

\title{
Time knowledge acquisition in children aged 6 to 11 years and its relationship with numerical skills
}

\author{
Florence Labrell ${ }^{\mathrm{a}, \mathrm{b}, *}$, Yann Mikaeloff ${ }^{\mathrm{a}, \mathrm{c}}$, Hervé Perdry $^{\mathrm{a}}$, Georges Dellatolas ${ }^{\mathrm{a}}$ \\ a Unité INSERM 669, Université Paris-Sud, Université Paris Descartes, 75006 Paris, France \\ ${ }^{\mathrm{b}}$ Université de Reims, 51100 Reims, France \\ ${ }^{\mathrm{c}}$ Unité de Rééducation Neurologique Infantile (URNI), Hôpital Bicêtre, Assistance Publique Hôpitaux de Paris (AP-HP), 94275 \\ Le Kremlin-Bicêtre, France
}

\section{A R T I C L E I N F O}

Article history:

Received 21 October 2014

Revised 5 October 2015

Available online $\mathrm{xxxx}$

\section{Keywords:}

Time knowledge

Numbers

Childhood

\begin{abstract}
A B S T R A C T
Acquisition of time knowledge (TK; the correct representation and use of time units) is linked to the development of numerical abilities, but this relationship has not been investigated in children. The current study examined the acquisition of TK and its association with numerical skills. A total of 105 children aged 6 to 11 years were interviewed with our Time Knowledge Questionnaire (TKQ), developed for purposes of this study, and the Zareki-R, a battery for the evaluation of number processing and mental calculation. The TKQ assessed conventional time knowledge (temporal orientation, temporal sequences, relationships between time units, and telling the time on a clock), estimation of longer durations related to birthday and life span, and estimation of the duration of the interview. Time knowledge increased with age, especially from 6 to 8 years, and was strongly linked to numerical skills. Regression analyses showed that four numerical components were implicated in TK: academic knowledge of numbers and number facts (e.g., reading Arabic numerals, mental calculation), number line estimation (e.g., correspondence between a number and a distance), contextual estimation (e.g., many/few leaves on a tree, children in a family), and numerical tasks involving verbal working memory (e.g., comparison of numbers presented orally). Numerical correlations with TK varied according to children's age; subtests based on academic knowledge of numbers, working memory, and number line estimation were linked with TK in the
\end{abstract}

* Corresponding author at: Unité INSERM 669, Université Paris-Sud, Université Paris Descartes, 75006 Paris, France. Fax: +33 0145595331 .

E-mail address: florence.labrell@univ-reims.fr (F. Labrell). 
younger children, but only contextual estimation was associated with TK in the older children.

(c) 2015 Elsevier Inc. All rights reserved.

\section{Introduction}

Many philosophers have explored the relationship between time and number-from Aristotle (384-322 B.C.), who wrote that "time is the number of movement in respect to the before and after" (Physics IV), to more recent thinkers such as Bergson (1889/1967), who claimed that number is related to space but not to our experience of time. The relationship between time and number has been less widely investigated by developmental psychologists.

Dealing with time is an absolute necessity to organize life in society (for work, meals, leisure, etc.) (Fraisse, 1957), and this has led to the creation of conventional unit systems. Children need to develop some knowledge about these systems even if they are starting to have a primitive "sense of time" linked to actions-time to go to bed, duration of a pleasant/unpleasant event, and so forth. Both aspects, the conventional system of time units and the sense of time, have been assimilated to time knowledge (Friedman, 1990a). Time knowledge (TK), precisely defined here as the correct representation and use of the various time units (e.g., seconds, minutes, hours, days, weeks, months, seasons, years), has not been widely studied, nor has its development. Whereas using time units implies a proper representation and use of numbers (e.g., "It is 10 o'clock on the 25th day of the 9th month in the year 2015"), children's development of time knowledge is logically linked to the development of their numerical competencies.

However, up to now, most studies have been devoted to time perception over short durations without using verbal answers involving time units (for a review, see Droit-Volet, 2013). These studies reveal that the ability to judge time precisely in a wide variety of temporal tasks improves during childhood via the development of selective attention and working memory (Droit-Volet \& Zelanti, 2013). As far as we know, the relationship between TK and numerical competencies has not been systematically examined in children, probably because of the lack of a tool for TK evaluation. Therefore, our aim was twofold: first, to study TK development during childhood and, second, to investigate the links between TK and children's numerical abilities. For the purposes of this study, we developed a Time Knowledge Questionnaire to evaluate the correct representation and use of the various time units.

\section{Evaluation of TK: previous and new components}

Different aspects of TK, such as present-time awareness, using a calendar (Fraisse, 1957; Friedman, 1990a; Godart \& Labelle, 1998), and telling the time on a clock (Burny, Valcke, \& Desoete, 2009; Cohen, Ricci, Kibby, \& Edmonds, 2000; Friedman \& Laycock, 1989; Vakali, 1991), have already been investigated in children. Present-time awareness, also called time orientation, is the awareness of the present hour, day, month, year, or season. Awareness of the present day is thought to be acquired at the end of kindergarten at around 6 years, whereas that of the present month, season, or year occurs later in primary school at 7 or 8 years (Friedman, 1990a).

Other aspects of TK, more related to the experience of time, have been less widely envisaged. For example, the representation of time units might depend on implicit learning, such as experiencebased knowledge (e.g., "A familiar activity takes $x$ minutes/seconds/hours"), which could be clinically relevant. Indeed, children with autistic spectrum disorders have been shown to perform less well than typically developing children when durations were to be compared (e.g., eating a banana, going to a swimming pool) (Janeslätt, Granlund, Kottorp, \& Almqvist, 2010).

Children's estimation of time during a long ongoing activity has rarely been studied (e.g., in the case of an interview duration, "For how long have we been here together?"), unlike children's percep- 
tion of short intervals (a few seconds), where children are asked, for instance, to reproduce the time interval (e.g., Droit-Volet, 2013) without a verbal answer in the form of a number of time units.

In addition, children's representations of the life span have rarely been investigated. Life-span representations have been explored in studies of children's conceptual development in biology. For instance, the understanding of irreversibility of growth for humans, animals, and plants has been explored in typically developing children (Inagaki \& Hatano, 1996; Labrell \& Stefaniak, 2011; Maurice-Naville \& Montangero, 1992; Rosengren, Gelman, Kalish, \& McCormick, 1991) and in pediatric populations such as survivors from cerebellar tumors (Labrell, Kieffer, Grill, \& Dellatolas, 2014). However, investigations examining how children estimate the duration of growth and ageing (e.g., between infancy and childhood, between childhood and adulthood, between adulthood and old age) are lacking.

Lastly, few studies have investigated time intervals based on birthdays, for instance, how children progressively orient themselves with respect to their own birthdays. According to Godart and Labelle (1998), 33\% of a sample of 9-year-olds made a correct estimation of the present-next birthday time interval versus $16 \%$ for the present-last birthday time interval.

As far as we know, none of the above dimensions (i.e., classic present-time awareness, telling the time on a clock, and explicit knowledge of time units), nor any of the less investigated dimensions (e.g., the estimation of (a) durations longer than a few seconds, (b) human life span intervals, and (c) birthday-based intervals), have ever been combined in the same tool. Consequently, correlations between all of these different aspects of TK during development are not well known, and it remains unclear how many different dimensions of TK (e.g., one or more than one) should be considered.

\section{Time knowledge: relationships with numerical skills and underlying mechanisms}

TK acquisition enables everyday time judgments. For instance, TK enables children to locate themselves in time, from the present moment to the more or less close past or future. The verbal sequences of days and months are learned during early primary school (Fraisse, 1957; Friedman, 1990a; Godart \& Labelle, 1998). According to Friedman (1983, 1984, 1986, 1990b), children first develop a list-based representation of the days and the months, relying on lexical working memory, before being able to use an analogous spatial representation of the time intervals between days and months. Moreover, these time sequences rely on logical reasoning, particularly seriation performance (Friedman, 1977), and involve an understanding of the linear and cyclic nature of time given that days and months not only occur but also recur in a specific order.

Location in time implies a correct use of time units (e.g., seconds, minutes, hours, days, weeks, months, seasons, years), relying both on the mastery of the verbal sequences of the time units and on the numerical abilities of counting (using forward and backward sequences) and mental calculation. Indeed, the sequences of time units are closely related to numbers, and especially to counting (e.g., days of the week, months, years, hours), but also to subtracting (e.g., "How long is it to my birthday from now?"). The Chinese calendar in particular is based on an arithmetical labeling of each day or month (e.g., March is "month three"), but many other languages also use arithmetical labels for the days of the week (e.g., in Portuguese: second, third, fourth, fifth, and sixth for Monday-Friday; in modern Greek: second, third, fourth, and fifth for Monday-Thursday).

Numbers are also involved in telling the time on a clock, which is a complex cognitive activity relying on mathematics, (Andersson, 2008; Burny, Valcke, \& Desoete, 2011; Cohen et al., 2000; Friedman \& Laycock, 1989; Vakali, 1991) as well as on several domains of competence such as language (Bock, Irwin, Davidson, \& Levelt, 2003), visuospatial skills (Eden, Wood, \& Stein, 2003), and conceptual representations (Burny et al., 2009). In particular, explicit knowledge of the relationships between time units (e.g., how many hours in a day, how many minutes in an hour) has been considered as a prerequisite for correct use of analogue and digital clocks (Burny et al., 2009, 2011; Cohen et al., 2000; Friedman \& Laycock, 1989). It has been shown that most children are able to read both analogue and digital clocks correctly at the age of 8 to 10 years (Burny et al., 2009).

Correct representation and use of time units is probably related not only to knowledge of numbers and computation but also to the so-called "cognitive estimation" of quantities (Harel, Cillessen, Fein, Bullard, \& Aviv, 2007). This cognitive estimation has at least two components: the first relating to the 
"theory of magnitude" and the second relating to contextual estimation. These two components are thought to rely on two different brain areas: the inferior parietal cortex and the frontal lobe, respectively.

First, it has been proposed that the estimation of the magnitude of a number and the estimation of a time interval rely on the same process (for a review, see Allman, Pelphrey, \& Meck, 2012)-a mode control model generating an estimate of the magnitude of a duration or nonsymbolic numerosity from an accumulation of "pulses" compared with stored criteria of a given duration or number (Meck \& Church, 1983; Meck, Church, \& Gibbon, 1985). Walsh (2003) proposed a theory of magnitude postulating that the same cognitive system, located in the inferior parietal cortex, is devoted to common processing mechanisms for the evaluation of time, number, and space. Several studies on the nonsymbolic "sense" of number and time showed a primitive time and number sense during infancy that is based on ratio (rather than absolute) differences in magnitude (Provasi, Rattat, \& Droit-Volet, 2011). One and the same developmental progression for temporal discrimination and number discrimination during infancy has been suggested (Brannon, Suanda, \& Libertus, 2007). The "triple code" model for numbers (i.e., verbal, Arabic, and analogical) also supposes an analogical representation associating a quantity with a number (Cohen \& Dehaene, 1996; Dehaene, 1992).

Second, the correct representation of time units might also be related to another "cognitive estimation" of quantities linked to everyday and contextualized activities. This concerns, for instance, the estimation of the time needed to carry out an activity, as in the Biber Cognitive Estimation Test (Bullard et al., 2004), also studied during childhood (Harel et al., 2007). These estimations are thought to rely on mental control and planning, which are generally considered to be frontal lobe functions (Shallice \& Evans, 1978), and not exclusively on "magnitude" given that the same quantity (e.g., 10) may be "a lot" (e.g., 10 children in the same family) or "a few" (e.g., 10 leaves on a big tree).

\section{Aims and hypotheses}

We investigated the development of most aspects of TK, from 6 to 11 years, and its link with children's numerical competencies. We hypothesized that TK development is not linear because the different numerical components are thought not to be acquired at the same age. Indeed, TK is likely to be linked to at least three aspects of numerical abilities: (a) the knowledge of numbers and number facts involved in devices that measure time such as clocks and calendars, (b) analogical estimation, and (c) contextual estimation. For example, we hypothesized that knowledge of numbers might be acquired earlier than contextual estimation, which is thought to rely on children's experience of everyday and contextualized activities. It can be recalled that the (b) and (c) aspects above are thought to be processed in two different brain areas.

Consequently, the links between TK and numerical abilities might be different according to children's age. Educated adults are expected to perform perfectly on TK when it concerns the usual time units (i.e., from seconds to years); however, most adults do not know that $10^{-24} \mathrm{~s}$ is a yoctosecond and that $10^{24} \mathrm{~s}$ is a yottasecond. As a consequence, correlations between usual TK and numeracy cannot be estimated in adults. In children, some subcomponents of number processing may be perfectly acquired by older children (e.g., counting, reading and writing Arabic numerals) but not by younger children. Conversely, other subcomponents of number processing (e.g., calculation) may show floor effects in younger children, making it difficult to estimate their correlation with TK, whereas this is not so among older children.

\section{Method}

Participants

The participants were 105 school children from Grade 1 to Grade 5, 57 girls (54\%) and 48 boys (46\%), aged 6.2 to 11.1 years. Each school grade corresponded to a different age range (see Table 1). Children were recruited in their schools, with informed consent to participate in the study obtained from both parents. Teachers asked children with no special educational needs or behavioral or neuro- 
Table 1

Participants' school grade, gender, and age.

\begin{tabular}{lllll}
\hline School grade & Age group (years) & $n$ & Girls $[n(\%)]$ & Age in years [mean $(S D)$, range] \\
\hline 1 & 6 & 17 & $8(47)$ & $6.41(0.14), 6.2-6.7$ \\
2 & 7 & 19 & $12(63)$ & $7.52(0.13), 7.2-7.7$ \\
3 & 8 & 26 & $13(50)$ & $8.71(0.26), 8.1-9.0$ \\
4 & 9 & 24 & $11(46)$ & $9.51(0.29), 9.0-10.0$ \\
5 & 10 & 19 & $13(68)$ & $10.58(0.29), 10.1-11.1$ \\
Total & & 105 & $57(54)$ & $8.65(1.40), 6.2-11.1$ \\
\hline
\end{tabular}

logical difficulties to join the sample. The participants came from a representative sample of the French population living in a relatively large city $(200,000$ inhabitants) near Paris. They were recruited via state schools.

\section{Materials}

Two tools were used: our ad hoc Time Knowledge Questionnaire (TKQ) (see Appendix A) and the Zareki-R (Neuropsychologische Testbatterie für Zahlenverarbeitung und Rechnen bei Kindern-R) (Von Aster \& Dellatolas, 2005; Von Aster, Deloche, Dellatolas, \& Meier, 1997). The Zareki-R enables measures of numerical skills (counting dots, dictation of numbers, reading numbers, and oral and written comparison of pairs of numbers), analogical representation of numbers (number line estimation), and cognitive estimation (contextual estimation). Some subtests (e.g., comparison of numbers presented orally) strongly depend on verbal working memory (see Appendix B).

\section{Time Knowledge Questionnaire}

The TKQ (Appendix A) comprises seven subtests. The first four subtests investigated conventional time knowledge: orientation (OR), sequences (SEQ), time units (TU), and telling the time on a clock $(\mathrm{CL})$, and comprised 5, 3, 4, and 5 questions, respectively. The questions about telling the time on a clock used pictures of five analogue clocks with five different positions of the minute and hour hands. Each answer was coded as correct ( 1 point) or incorrect ( 0 points), for a total conventional time score from 0 to 17.

The fifth subtest, life span (LS), used four pictures (a baby, a child, a young man, and an old man) illustrating the biological process of ageing (see Fig. 1). A fair-haired man, depicted at four different stages in development from infancy to old age, was chosen. The child was asked three questions about the time required to go from one age to the next (i.e., from baby to child, from child to young man, and from young man to old man). Each answer was coded as 0,1 , or 2 points. The coding rule was based on the answers of 20 adults that were as follows: from baby to child, median $=6$ years, range $=4$ to 10 ; from child to young man, median $=22$ years, range $=15$ to 30 ; from young man to old man, med-
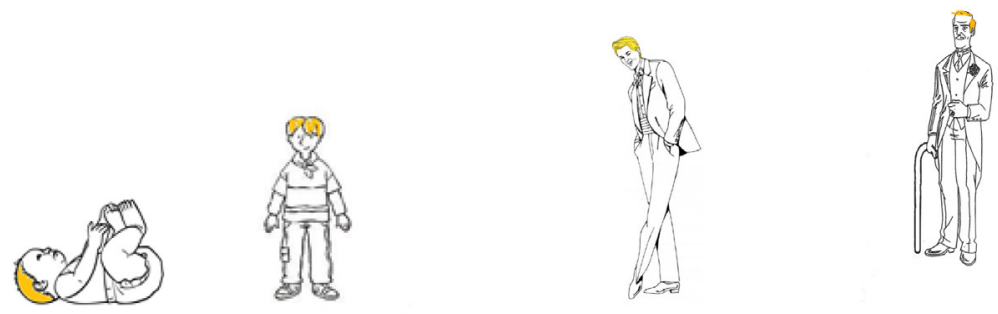

Fig. 1. Material for the life-span questions. 
ian $=35$ years, range $=20$ to 55 . Two points were given if the child answered in the adult range. One point was given if the answer was borderline (i.e., not in the adult range but not clearly impossible), that is, within the following intervals: baby-child, 2 to 3.99 and 10.01 to 15 years; child-young man, 5 to 14.99 and 30.01 to 40 years; young man-old man, 55.01 to 90 years. No points were given for answers outside of these ranges or for "don't know" answers (total LS score from 0 to 6).

The sixth subtest, birthday (BIR), comprised six questions. Questions 1 to 3 ("How old are you?", "What age were you last year?", and "How old will you be next year?") were not taken into account in the calculation of the score because the answers were invariably "correct" (i.e., the absolute difference between the given age and the exact age was always less than 1 year). The other three questions regarding birthdays were "When is your birthday?", "How long ago was your birthday?", and "How long is it to your next birthday?" For these three questions, the correct answer was available (for each child, date of birth and date of interview were recorded), which made it possible to use a coding for error. Zero points were given if the child did not know the date of his or her birthday. Otherwise, for both of the last two questions (i.e., time intervals to the previous and next birthdays), 0 points were given for "don't know" and answers exceeding 12 months, and 1, 2, and 3 points were given for errors (i.e., absolute difference between the answer and the correct interval) greater than 3 months, between 3 months and 1 month, and less than 1 month, respectively (i.e., total BIR score from 0 to 6 ).

The last subtest was interview duration (ID). At the end of the interview, the examiner asked the child, "For how long have we been here together?" The median duration of the interview was 15 min (Q3-Q1 = 14-21 min, range = 5-42). Zero points were given for "don't know" answers. For all other answers, 0 to 10 points were given according to the absolute difference between the log of the real duration of the interview and the log of the answer (in minutes) (see Appendix $C$ for an illustration of this scoring method).

Two subtests from the TKQ, sequences and time units, were based on a previous study on time conceptions in children treated for malignant cerebellar tumors (Labrell et al., 2014) given that the cerebellum has been implicated in time perception. Other dimensions linked to time knowledge, such as children's estimation of the duration of several daily activities (e.g., brushing their teeth, going from home to school), were investigated in this earlier study but were not retained in the current study for psychometric reasons (insufficient internal consistency). In the previous study, we were also interested in children's understanding of time in the biological process of growth. Therefore, we used the same pictures from the life span subtest, but we did not ask for the time lapse between the different stages.

\section{Zareki-R}

The Zareki-R (Appendix B) is a battery for the evaluation of number processing and mental calculation in school children. It contains 11 subtests evaluating knowledge of the verbal sequence of numbers and acquisition of the principles of counting (counting dots and counting backward), knowledge of the oral and written forms of numbers (reading numbers and writing numbers under dictation, comparison of numbers, all written presentations of numbers in Arabic numerals, and comparison of numbers presented orally), mental calculation (orally presented additions, subtractions, and multiplications), problem solving (presented orally), number line estimation (positioning integers $>0$ and $<100$ on a $0-100$ line), perceptual estimation (giving the approximate number of elements seen without counting), and contextual estimation (deciding whether a given number in a given situation is "a few," "a medium number," or "a lot").

\section{Procedure}

The experimenter interviewed each child separately at his or her school in a quiet room, with the order of presentation of each tool being random. Sessions lasted approximately $50 \mathrm{~min}$. For the TKQ the experimenter asked the child to answer the interview questions from the pictures for telling the time on a clock and life span with no time limit. However, the experimenter recorded the time at the beginning of the TKQ and also at the end, in order to compute the error for the final interview duration answer. The child's answers were fully transcribed. 
For the Zareki-R, the experimenter used the test as scheduled in the handbook, that is, with visual material when required (for counting dots, reading numbers, number line estimation, perceptual estimation, and written comparison).

\section{Results}

TKQ subtests in relation to children's age: generation of a total TKQ score

A total TKQ score (TKS) was computed, summing the scores on each subtest ( $\max =39$ points; see Table 2) as well as three partial scores for conventional time (sum of the first four subtests), long durations (sum of the birthday and life span subtests), and interview duration.

Performance increased with age for all of the subtests in the TKQ $(p<.001$ in all cases). Table 2 shows a comparison of the means of the subtests and the total TKQ scores across the five age groups. For the TKS, post hoc comparison of the means (Scheffé test) showed significant differences across all successive age groups except between the 8- and 9-year age groups. For the subcomponents of the TKQ the improvement between the 6- and 7-year age groups was always significant except for life span (see Table 2 for more details of the post hoc comparison of the means).

Correlations across the seven subtests were all positive and significant at $p<.001$ (Cronbach's alpha $=.86$ ). A principal components analysis confirmed the unidimensional structure of the TKQ (first factor explaining $54 \%$ of the variance, loading of the seven subtests on the first factor between .63 and .83 , and eigenvalue of the second factor $<1$ ), justifying the computation of a total TKQ score. However, when age was partialed out, some partial correlations between the first four conventional time knowledge subtests and the last three subtests were close to 0 (e.g., between telling the time on a clock and birthday or life span). The age-adjusted alpha was .66 (see Table 3 ).

The correlation between total TKQ score and total Zareki-R score was high (.84) and remained high when age was partialed out (.60). All 11 subtests in the Zareki-R were positively correlated with the total TKQ score, with Pearson's $r$ values ranging from .33 (perceptual estimation) to .77 (reading numbers). These correlations remained significant when age was taken into account except for perceptual estimation and written comparison.

In summary, the greatest improvement in time knowledge was observed between the 6- and 7year age groups and, to a lesser extent, between the 7- and 8-year age groups, with only a slight improvement after 8 years. However, the developmental pattern was different according to the subtest. For instance, orientation (present-time awareness) exhibited a ceiling effect in children from 7 years of age; in contrast, estimation of interview duration continued to improve between the 9and 10-year age groups. The TKQ showed a unidimensional structure, justifying the computation of only one score summing the subscores; however, this was partly due to the correlation of all the sub-

Table 2

Means (and standard deviations) of the subtests in the TKQ according to children's age.

\begin{tabular}{llllllllll}
\hline Age group: $(n):$ & Max & $\begin{array}{l}6-7 \\
(17)\end{array}$ & $7(19)$ & $8(26)$ & $9(24)$ & $10(19)$ & $\begin{array}{l}\text { Total } \\
(105)\end{array}$ & $\begin{array}{l}F \\
(4,100)\end{array}$ & $p$ \\
\hline Orientation (OR) & 5 & $3.6(1.2)$ & $4.7(0.6)$ & $4.9(0.3)$ & $4.9(0.4)$ & $5.0(0.0)$ & $4.6(0.8)$ & 16.4 & $<.001$ \\
Sequences (SEQ) & 3 & $0.9(0.8)$ & $2.1(1.0)$ & $2.4(0.7)$ & $2.5(0.6)$ & $2.9(0.3)$ & $2.2(0.9)$ & 18.3 & $<.001$ \\
Time units (TU) & 4 & $1.7(0.9)$ & $3.1(0.8)$ & $3.7(0.7)$ & $3.8(0.5)$ & $3.9(0.2)$ & $3.3(1.0)$ & 35.9 & $<.001$ \\
Telling the time on a clock & 5 & $2.1(1.6)$ & $3.7(1.0)$ & $3.7(0.9)$ & $4.3(0.6)$ & $4.9(0.3)$ & $3.8(1.3)$ & 21.6 & $<.001$ \\
$\quad(\mathrm{CL})$ & & & & & & & & & \\
Life span (LS) & 6 & $2.1(2.0)$ & $3.7(2.2)$ & $4.8(1.5)$ & $4.6(1.5)$ & $5.2(0.8)$ & $4.2(1.9)$ & 10.2 & $<.001$ \\
Birthday (BIR) & 6 & $1.6(2.0)$ & $3.8(2.0)$ & $4.7(1.5)$ & $5.2(1.1)$ & $5.5(0.7)$ & $4.3(2.0)$ & 19.7 & $<.001$ \\
Interview duration (ID) & 10 & $4.0(3.6)$ & $5.7(3.6)$ & $8.2(1.5)$ & 7.10 & 8.90 & $6.94(3.1)$ & 10.4 & $<.001$ \\
& & & & & $(2.7)$ & $(1.2)$ & & & \\
Total score (TKS) & 39 & 15.9 & 26.9 & 32.3 & 32.3 & 36.3 & 29.38 & 50.5 & $<.001$ \\
& & $(6.0)$ & $(7.0)$ & $(4.1)$ & $(3.1)$ & $(2.1)$ & $(8.1)$ & & \\
\hline
\end{tabular}

Note. Significant age effect at $p<.0001$ for all six subscores. Post hoc comparison of the means (Scheffé test): OR, SEQ, TU, CL, BIR, ID, TKS: $6<7,8,9,10$; LS: $6<8,9,10$; TU, ID, and TKS: $7<8,9,10$; BIR: $7<10$; CL: $7,8<10$; ID and TKS: $8,9<10$. 
Table 3

Correlations and age-adjusted partial correlations between the "time" subtests.

\begin{tabular}{|c|c|c|c|c|c|c|}
\hline & SEQ & $\mathrm{TU}$ & $\mathrm{CL}$ & LS & BIR & ID \\
\hline OR & $.50(.29)$ & $.52(.28)$ & $.49(.26)$ & $.38(.19)$ & $.47(.23)$ & $.32(.10)$ \\
\hline SEQ & & $.59(.32)$ & $.52(.25)$ & $.38(.13)$ & $.64(.43)$ & $.43(.21)$ \\
\hline TU & & & $.56(.23)$ & $.51(.27)$ & $.59(.29)$ & $.45(.19)$ \\
\hline CL & & & & $.29(.02)$ & $.38(.003)$ & $.36(.09)$ \\
\hline LS & & & & & $.57(.39)$ & $.33(.14)$ \\
\hline BIR & & & & & & $.44(.21)$ \\
\hline
\end{tabular}

Note. $p<.05$ if $r>.20 ; p<.01$ if $r>.25 ; p<.001$ if $r>.32$; alpha $=.86$; age-adjusted alpha $=.66$. OR, orientation; SEQ sequence; $\mathrm{TU}$, time units; CL, telling the time on a clock; LS, life span; BIR, birthday; ID, interview duration.

tests with age. Within each age group, it remains questionable whether the TKQ can be considered as unidimensional.

\section{Overall observed correlations between the TKQ score and the Zareki-R score}

A linear regression with TKQ score as the dependent variable and the 11 Zareki-R subtests as explanatory variables showed that four subtests remained significant at $p<.05$ : reading numbers, number line estimation, oral comparison, and contextual estimation. A backward selection confirmed that these four subtests explained 75\% of the variance of the total TKQ score, which was almost the same as the percentage of variance explained by the 11 subtests (77\%) (see Table 4 ).

The same regressions with backward selection ( $p<.01$ for a variable to be retained) were performed with dependent variables in the form of three partial scores on the TKQ: a "conventional time score" (CTS, the sum of the four first subtests in the TKQ), a "long durations" score (LDS, the sum of the birthday and life span subtests), and the interview duration score (IDS). The subtests in the Zareki-R selected were only one subtest for IDS (number line estimation), two subtests for LDS (reading numbers and contextual estimation), and three subtests for CTS (mental calculation, reading numbers, and contextual estimation).

In sum, these results show a strong association between time knowledge and number processing in typically developing children. Furthermore, the results also suggest that different cognitive processes involved in time processing influence TK (number knowledge, perception of magnitude, contextual estimation, and verbal working memory involved in number comparisons).

Table 4

Relationships of the total time score with the subtests and the total score of the Zareki-R number processing and calculation battery.

\begin{tabular}{|c|c|c|c|c|c|c|c|c|}
\hline & \multicolumn{2}{|c|}{$\begin{array}{l}\text { Correlation } \\
\text { with TKQ } \\
\end{array}$} & \multicolumn{3}{|c|}{ Linear regression $\left(R^{2}=.77\right)$} & \multicolumn{3}{|c|}{ Backward selection $\left(R^{2}=.75\right)$} \\
\hline & $r$ & $r_{\mathrm{p}}^{\mathrm{a}}$ & $b$ & $S(b)$ & $p$ & $b$ & $S(b)$ & $p$ \\
\hline Counting dots & .28 & .27 & .57 & .53 & .28 & & & \\
\hline Counting backward & .53 & .28 & .08 & .48 & .86 & & & \\
\hline Number dictation & .77 & .45 & .19 & .22 & .40 & & & \\
\hline Mental calculation & .74 & .42 & .03 & .07 & .67 & & & \\
\hline Reading numbers & .79 & .53 & .53 & .26 & .04 & .67 & .14 & $<.001$ \\
\hline Number line estimation & .74 & .52 & .45 & .15 & .005 & .39 & .14 & $<.006$ \\
\hline Oral comparison & .62 & .52 & .45 & .21 & .03 & .53 & .20 & $=.01$ \\
\hline Perceptual estimation & .33 & .10 & .13 & .46 & .78 & & & \\
\hline Contextual estimation & .66 & .35 & .67 & .21 & .002 & .81 & .18 & $<.001$ \\
\hline Problem solving & .72 & .35 & .12 & .20 & .54 & & & \\
\hline Written comparison & .49 & .13 & .67 & .35 & .06 & & & \\
\hline Total Zareki-R & .84 & .60 & & & & & & \\
\hline
\end{tabular}

a Age-adjusted partial correlation. 
Correlations between the Zareki subscores and the total TKQ score according to children's age

Correlations between subtests in the Zareki-R and total TKQ score varied according to age (Table 5). No clear pattern appeared in the younger children (6 years), who showed floor effects in many subtests. In the older children (10 years), contextual estimation was the only subtest showing a strong positive link with TKS. Reading numbers was linked with TKS at 7 years, oral comparison at 7 and 8 years, and positioning a number on a scale at 7 and 9 years. In summary, these results suggest that associations of TK with specific number processing subtests change with age.

\section{Discussion}

The current study in typically developing school children aged 6 to 11 years describes the development of TK and analyzes the relationships between overall TK development and numerical skills. The proposed definition of TK (i.e., the correct representation and use of the various time units) implies numbers. We hypothesized that TK is linked to at least three aspects of numerical abilities: the knowledge of numbers, analogical estimations, and contextual estimations.

\section{Development of time knowledge}

The TKQ used for the evaluation of TK included subtests widely investigated in previous studies in typically developing children (for orientation or present-time awareness, see Friedman, 1983, 1984, 1990b; for temporal sequences, see Friedman, 1977, 1986, 1990b; for telling the time on a clock, see Burny et al., 2009; Cohen et al., 2000; Friedman \& Laycock, 1989; Vakali, 1991) and also new subtests such as those exploring children's representation of long durations (life span and birthday). Despite this seemingly heterogeneous composition, the TKQ showed a relatively unidimensional structure, justifying the generation of a total score. However, this one-factor solution was partially attributable to age differences, as suggested by the lower age-adjusted partial correlations between the subtests and especially the partial correlations close to 0 between some conventional TK subtests (telling the time on a clock) and the subtests concerning long durations (birthday and life span). This observation led to the generation of three partial scores in addition to the total TKQ score: a conventional time score (sum of the first four subtests), a long duration score (sum of birthday and life span), and the interview duration score.

A strong age effect on all subtests in the TKQ was observed as well as many developmental patterns already reported in previous studies. For example, Friedman $(1977,1990 \mathrm{~b})$ provided evidence that

Table 5

Correlations (Pearson $r$ ) of the Zareki-R subtests with TKS by age.

\begin{tabular}{llllll}
\hline & 6 years $(n=17)$ & 7 years $(n=19)$ & 8 years $(n=26)$ & 9 years $(n=24)$ & 10 years $(n=19)$ \\
\hline Counting dots & .41 & .44 & -.005 & .08 & .30 \\
Counting backward & .28 & .11 & .05 & .21 & $-.46^{*}$ \\
Number dictation & $-51^{*}$ & $.49^{* *}$ & .09 & .16 & -.22 \\
Mental calculation & .32 & .40 & .34 & -.07 & .24 \\
Reading numbers & .05 & $.75^{* * *}$ & .20 & .03 & -.05 \\
Number line estimation & .22 & $.84^{* * *}$ & .24 & $.61^{* *}$ & -.06 \\
Oral comparison & .22 & $.84^{* * *}$ & $.53^{* *}$ & .30 & .03 \\
Perceptual estimation & .28 & -.11 & .21 & -.11 & -.08 \\
Contextual estimation & .08 & .36 & .34 & $.41^{*}$ & $.82^{* * *}$ \\
Problem solving & $.57^{*}$ & .34 & .30 & -.12 & .35 \\
Written comparison & -.39 & .26 & .15 & .04 & - \\
Total Zareki-R & .26 & $.69^{* * *}$ & $.43^{*}$ & .26 & .31 \\
\hline
\end{tabular}

\footnotetext{
${ }^{*} p<.05$.

*** $p<.01$.

*** $p<.001$.
} 
children master time orientation at around 7 years of age. Indeed, knowledge of numbers on which time orientation depends is largely school dependent.

In contrast, the children's precise representation of life-span intervals (LS subtest) scored lower than in adults even at 10 years of age. Accurate estimation of the three time intervals (baby-child, child-young man, and young man-old man) appeared to be a very difficult task for young children. It can be considered that, in order to succeed in the LS subtest, respondents need to attribute an age to each stage and also to perform a subtraction (e.g., age of the adult minus age of the child) in the same manner as adults do. The age for mastering subtraction in French children is approximately 8 years (Von Aster \& Dellatolas, 2005). Correct estimations of the probable age of each human figure (the baby, the child, the young man, and the old man) have not been studied in children's biological conceptions and might depend on their experience of the real world.

The results about birthdays showed that the children were capable of accurately identifying their birthdays only during the primary school years. This progression in children's ability to position their birthdays in time, based on past and future events, corroborates Friedman's (2000) findings regarding children's knowledge of the time to future events as occurring between 7 and 10 years.

\section{Relationships between time knowledge and numerical skills}

The total TKQ score was strongly related to numerical skills, explaining $70.6 \%$ of the variance $(r=.84)$ when only the total Zareki-R score was considered and $77 \%$ of the variance when performances on the 11 numerical subtests were considered. Regression analyses showed that four numerical subtests explained an almost equivalent proportion of the variance (75\%): reading numbers, number line estimation, contextual estimation, and comparison of numbers presented orally.

When the three partial TKQ total scores (rather than the total TKQ score) were the dependent variables, the same subtests in the Zareki-R were selected. Number line estimation was the only subtest retained for IDS; mental calculation, reading numbers, and contextual estimation were retained for CTS; and reading numbers and contextual estimation were retained for LDS. In other words, as hypothesized, TK was found to be predicted by different numerical skills.

Each of these numerical predictors of TK represents a different domain of numerical skills. For the conventional time score, reading numbers and mental calculation are clearly school dependent, as is knowledge of the relationships between time units (e.g., "One hour is 60 minutes"). To master time sequences or units, and to tell the time on a clock correctly, children need to compute with numbers.

The regression analysis predicted the interview duration score only from number line estimation, which requires a quantity to be associated with a number (Dehaene, 1992). Indeed, to solve this task, children need to master the analogical representation of the "triple code" model (Cohen \& Dehaene, 1996). In other words, children encountering difficulties in evaluating the passage of time need to be trained in the analogy between quantity and number.

The predictors of long duration score were reading numbers (necessary to identify ages of life span and birthday) and contextual estimation. This numerical ability involves an accurate judgment about quantities, whereby a large number may be "a few" (e.g., 200 fans at a football game) and a small number may be "a lot" (e.g., 10 children in a family). The ability to make such judgments requires general knowledge of the world. This knowledge is needed to answer some items in the TKQ correctly. For example, when children are asked to evaluate the duration of developmental periods (from infancy to childhood, from childhood to adulthood, and from adulthood to old age), they need to know how time is involved in human growth and also that the change in appearance is not proportional to the time intervals. According to Shallice and Evans (1978), contextual estimation is based on executive functions. These functions are also involved in conventional time knowledge (e.g., to answer questions such as "Can you tell me the seasons of the year in order?" and "Is a month shorter or longer than a year?"), and they are also needed to estimate the time required to plan daily activities (Harel et al., 2007).

Lastly, the results about the relationships between TK development and numerical skills according to children's age have shown that, as predicted, the significant numerical subtests were not the same according to children's age. First, reading numbers, number line estimation, and especially oral comparison were the subtests that were most correlated with the total TKQ score for the youngest children 
(i.e., 7 and 8 years). Indeed, working memory, which is involved in oral comparison, is the executive function young children need to answer all of the subcomponents in the TKQ (i.e., present-time awareness, telling the time on a clock, birthday, life span, and duration of the interview). Second, number line estimation was the most strongly correlated subtest with the total TKQ score among children from 9 years. For these children, time knowledge appeared to be mostly linked to the ability to associate a quantity with a number, as for the birthday, life span, and duration of the interview subtests. Third, contextual estimation, thought to rely on children's general knowledge of the world, was the most strongly correlated subtest with the total TKQ score in 10-year-old children, the oldest group.

\section{Limitations and perspectives}

Due to ceiling effects for some subtests in the TKQ (e.g., orientation) and to floor effects for others (e.g., life span), interpretation of the results of the correlation analyses according to children's age should be made with caution. Further studies are needed with more participants by age group in order to (a) propose new versions of the TKQ better adapted to each age group and (b) examine whether the structure of the TKQ is unidimensional or not within each age group.

Future studies should investigate the role of cognitive factors, especially verbal skills, in the relationship between time knowledge and numerical skills. The above-mentioned four components of the Zareki-R involved in time knowledge may be differentially impaired in children with developmental disorders such as children with developmental dyslexia, specific language impairment (Gooch, Snowling, \& Hulme, 2011; Helland \& Asbjornsen, 2003), or specific nonverbal deficits. Studies in these special populations of children could clarify the roles of language, reading, and/or visuospatial skills in TK acquisition.

\section{Appendix A. The Time Knowledge Questionnaire}

Orientation (OR): (1) What day is it today? (2) What time is it**? (3) In what month are we? (4) In what year are we? (5) In what season are we?

Sequences (SEQ): (1) What month comes after March? (2) Can you tell me the months in the year in order? (3) Can you tell me the seasons in the year in order?

Time units (TU): (1) Is a minute shorter or longer than a second? (2) Is a week longer or shorter than a month? (3) Is a month shorter or longer than a year? (4) How many hours are there in one day, from one day in the morning to the next day in the morning?

Telling the time on a clock (CL) (six images of a clock): (1) Show me 2 o'clock. (2) Show me 10 to 3. (3) Show me a quarter past 8. (4) Show me 10 past 11. (5) Look at this clock. How many minutes is it to 2 o'clock?

Life span (LS) (four pictures: baby, child, young man, and old man): How long does it take: (1) for a baby (here) to become a child (here)? (2) for a child (here) to become a young man (here)? (3) for a young man to become an old man?

Birthday (BIR): (1)* How old are you? (2)* When is your birthday? (3) How long ago was your birthday? (4) How long is it to your next birthday?

Interview duration (ID): (1) For how long have we been here together?

${ }^{*}$ Questions not considered in the calculation of subscores and total score.

${ }^{* *}$ Considered as correct if the child's answer is in the same half day (if it is 10 o'clock and the answer is "it is 8 o'clock" or "it is midday," the child's answer is considered as correct, but if the child's answer is "it is 4 p.m.," it is considered as incorrect).

\section{Appendix B. The 11 subtests of the Zareki-R}

Counting dots (CoDo): Presented on six cards with 13, 5, 15, 10, 8, and 18 dots, respectively. Score from 0 to 6 .

Counting backward (CoBa): From 23 to 1 and from 67 to 54 . Score from 0 to 4 . 


\begin{tabular}{llllll}
\hline Case & Real ID (a) (min) & Answer $(\mathrm{b})(\mathrm{min})$ & Error: $|\log (\mathrm{a})-\log (\mathrm{b})|$ & Range of the error & Score \\
\hline 1 & 17 & Don't know & & & 0 \\
2 & 33 & 1 & 1 & 1 & 0 \\
3 & 18 & 2 & .95 & $.90-.99$ & 1 \\
4 & 21 & 3 & .85 & $.80-.89$ & 2 \\
5 & 22 & 4 & .74 & $.70-.79$ & 3 \\
6 & 22 & 5 & .64 & $.60-.69$ & 4 \\
7 & 17 & 5 & .53 & $.50-.59$ & 5 \\
8 & 10 & 30 & .48 & $.40-.49$ & 6 \\
9 & 15 & 30 & .30 & $.30-.39$ & 7 \\
10 & 18 & 10 & .26 & $.20-.29$ & 8 \\
11 & 15 & 10 & .18 & $.10-.19$ & 9 \\
12 & 20 & 25 & .097 & $<.10$ & 10 \\
13 & 15 & 15 & 0 & $<.10$ & 10 \\
\hline
\end{tabular}

Dictation of number (DicNu): Oral presentation of eight numbers to be written in Arabic numerals: $14,38,1200,503,169,4658,756$, and 689. Score from 0 to 16.

Mental calculation (Calc): Oral presentation of eight additions $(5+8,12+6,4+13,9+7,15+12$, $13+19,14+8$, and $17+25)$, eight subtractions $(17-5,14-6,24-17,19-6,15-9,25-12$, $32-17$, and $18-11)$, and six multiplications $(3 \times 2,4 \times 5,3 \times 4,2 \times 6,5 \times 3$, and $4 \times 4)$. Score from 0 to 44 .

Reading numbers (Read): Reading eight numbers written in Arabic numerals: 15, 57, 1900, 305, 138, 6485, 687, and 969. Score from 0 to 16.

Number line estimation (NumLi): On vertical lines presented with a 0 at the bottom and a 100 at the top, the child is asked to mark the positions of 12 numbers: $86,48,5,32,93,62,53,27,76,17$, 59, and 83. Score from 0 to 24 .

Oral comparison (OrComp): The child must say which one of the two numbers presented orally in eight pairs is the larger of the pair: 51/49, 465/546, 2009/2090, 108/800, 612/389, 800/108, $34601 / 9678,46 / 64$, and 1086/322. Score from 0 to 16.

Contextual estimation (ContEs): The child must evaluate whether 10 situations such as "four teachers in the same classroom," "two clouds in the sky," "three children in the same family," "10 leaves on a tree," and "eight lamps in the same room" are "a small number," "a medium number," or "a lot." Score from 0 to 10 .

Perceptual estimation (PercEs): The child must give an approximation of the number of dots seen (on two cards presented for $2 \mathrm{~s}$ each), the number of balls (on one card presented for $5 \mathrm{~s}$ ), and the number of glasses (on one card presented for $5 \mathrm{~s}$ ). The presentation time does not enable complete counting. Score from 0 to 5 .

Problem solving (Prob): The child must solve six numerical problems of increasing difficulty presented orally. For example, the first problem is, "Peter has 12 marbles. He gives 5 to his friend Ann. How many marbles does Peter have now?" Score from 0 to 12.

Written comparison (WritComp): The child must say which of two numbers presented in 10 written pairs is the larger of the pair: 13/31, 79/81, 1007/1070, 511/298, 654/546, 9768/35201, 96/69, 201/102, 347/947, and 1238/11238. Score from 0 to 10.

\section{Appendix C. Scoring of the error between real interview duration (ID) and child's answer}




\section{References}

Allman, M. J., Pelphrey, K. A., \& Meck, W. H. (2012). Developmental neuroscience of time and number: Implications for autism and other neurodevelopmental disabilities. Frontiers in Integrative Neuroscience, 6. http://dx.doi.org/10.3389/ fnint.2012.00007.

Andersson, U. (2008). Mathematical competencies in children with different types of learning difficulties. Journal of Educational Psychology, 100, 48-66.

Bergson, H. (1967). Essais sur les Données Immédiates de la Conscience (Original doctoral dissertation 1889). Paris: Presses Universitaires de France.

Bock, K., Irwin, D. E., Davidson, D. J., \& Levelt, W. J. M. (2003). Minding the clock. Journal of Memory and Language, 48, 653-685.

Brannon, E. M., Suanda, S., \& Libertus, K. (2007). Temporal discrimination increases in precision over development and parallels the development of numerosity discrimination. Developmental Science, 10, 770-777.

Bullard, S. E., Fein, D., Gleeson, K. M., Tischer, N., Mapou, R. L., \& Kaplan, E. (2004). The Biber cognitive estimation test. Archives of Clinical Neuropsychology, 19, 835-846.

Burny, E., Valcke, M., \& Desoete, A. (2009). Towards an agenda for studying learning and instruction focusing on time-related competences in children. Educational Studies, 35, 481-492.

Burny, E., Valcke, M., \& Desoete, A. (2011). Clock reading: An underestimated topic in children with mathematics difficulties. Journal of Learning Disabilities, 45, 351-360.

Cohen, L., \& Dehaene, S. (1996). Cerebral networks for number processing: Evidence from a case of posterior callosal lesion. Neurocase, 2, 155-174.

Cohen, M. J., Ricci, C. A., Kibby, M. Y., \& Edmonds, J. E. (2000). Developmental progression of clock face drawing in children. Child Neuropsychology, 6, 64-76.

Dehaene, S. (1992). Varieties of numerical abilities. Cognition, 44, 1-42.

Droit-Volet, S. (2013). Time perception in children: A neurodevelopmental approach. Neuropsychologia, 51, 220-234.

Droit-Volet, S., \& Zelanti, P. S. (2013). Development of time sensitivity and information processing speed. PLoS ONE, 8(8), e71424.

Eden, G. F., Wood, F. B., \& Stein, J. F. (2003). Clock drawing in developmental dyslexia. Journal of Learning Disabilities, 36 , 216-228.

Fraisse, P. (1957). Psychologie du temps. Paris: Presses universitaires de France.

Friedman, W. J. (1977). The development of children's understanding of cyclic aspects of time. Child Development, 48, 1593-1599.

Friedman, W. J. (1983). Image and verbal processes in reasoning about the months of the year. Journal of Experimental Psychology: Learning, Memory, and Cognition, 9, 650-666.

Friedman, W. J. (1984). Analog and semantic models of judgments about the months of the year. Memory E Cognition, 12, 306-313.

Friedman, W. J. (1986). The development of children's knowledge of temporal structure. Child Development, 57, 1386-1400.

Friedman, W. J. (1990a). About time: Inventing the fourth dimension. Cambridge, MA: MIT Press.

Friedman, W. J. (1990b). Children's representations of the pattern of daily activities. Child Development, 61, 1399-1412.

Friedman, W. J. (2000). The development of children's knowledge of the times of future events. Child Development, 71, 913-932.

Friedman, W. J., \& Laycock, F. (1989). Children's analog and digital clock knowledge. Child Development, 60, 357-371.

Godart, L., \& Labelle, M. (1998). Le développement de la localisation dans le temps chez des enfants de 5 à 9 ans de milieux socio-économiques différents. L'Année Psychologique, 98, 233-270.

Gooch, D., Snowling, M., \& Hulme, C. (2011). Time perception, phonological skills and executive function in children with dyslexia and/or ADHD symptoms. Journal of Child Psychology and Psychiatry, 52, 195-203.

Harel, B. T., Cillessen, A. H. N., Fein, D. A., Bullard, S. E., \& Aviv, A. (2007). It takes nine days to iron a shirt: The development of cognitive estimation skills in school age children. Child Neuropsychology, 13, 309-318.

Helland, T., \& Asbjornsen, A. (2003). Visual-sequential and visuo-spatial skills in dyslexia: Variations according to language comprehension and mathematics skills. Child Neuropsychology, 9, 208-220.

Inagaki, K., \& Hatano, G. (1996). Young children's recognition of commonalities between animals and plants. Child Development, 67, 2823-2840.

Janeslätt, G., Granlund, M., Kottorp, A., \& Almqvist, N. (2010). Patterns of time processing ability in children with and without developmental disabilities. Journal of Applied Research in Intellectual Disabilities, 23, 250-262.

Labrell, F., Kieffer, V., Grill, J., \& Dellatolas, G. (2014). Conceptions of time in children treated for malignant cerebellar tumors. Brain Injury, 28, 1334-1341.

Labrell, F., \& Stefaniak, N. (2011). The development of diachronic thinking between 6 and 11 years: The case of growth and death. International Journal of Behavioral Development, 35, 532-541.

Maurice-Naville, D., \& Montangero, J. (1992). The development of diachronic thinking: 8-12-Year-old children's understanding of the evolution of forest disease. British Journal of Developmental Psychology, 10, 365-383.

Meck, W. H., \& Church, R. M. (1983). A mode control model of counting and timing processes. Journal of Experimental Psychology: Animal Behavior Processes, 9, 320-334.

Meck, W. H., Church, R. M., \& Gibbon, J. (1985). Temporal integration in duration and number discrimination. Journal of Experimental Psychology: Animal Behavior Processes, 11, 591-597.

Provasi, J., Rattat, A.-C., \& Droit-Volet, S. (2011). Temporal bisection in 4-month-old infants. Journal of Experimental Psychology: Animal Behavior Processes, 37, 108-113.

Rosengren, K. S., Gelman, S. A., Kalish, C. W., \& McCormick, M. (1991). As time goes by: Children's early understanding of growth in animals. Child Development, 62, 1302-1320.

Shallice, T., \& Evans, M. (1978). The involvement of the frontal lobes in cognitive estimation. Cortex, 14, $294-303$.

Vakali, M. (1991). Clock time in seven- to ten-year-old children. European Journal of Psychology of Education, 6, 325-336.

Von Aster, M., \& Dellatolas, G. (2005). Zareki-R (Neuropsychologische Testbatterie für Zahlenarbeitung und Rechnen bei Kindern-R). Paris: Éditions du Centre de Psychologie Appliquée. 
Von Aster, M., Deloche, G., Dellatolas, G., \& Meier, M. (1997). Number processing and calculation in 2nd and 3rd grade school children: A comparative study of French-speaking and German-speaking children. Zeitschrift für Entwicklungspsychologie und Pädagogische Psychologie, 24, 151-166.

Walsh, V. (2003). A theory of magnitude: Common cortical metrics of time, space, and quantity. Trends in Cognitive Sciences, 7 , 483-488. 